\title{
Examination of the antioxidant effects of pre-HSG melatonin use on ovarian surface epithelium in rats: An experimental study
}

\author{
Esra Sayglı Y.lmaz ${ }^{1, A-F}$, Tansel Sapmazz 2,B,B, , Halil Kazgan ${ }^{1, A, B}$, Şule Menziletoglu Yildiz ${ }^{4, A, D}$, \\ Derya Kocamaz, ${ }^{4, A, D}$, Nusret Akpolat ${ }^{5, C, E}$, Ekrem Sapmaz ${ }^{1, C, F}$ \\ ${ }^{1}$ Department of Gynecology and Obstetrics, Adana Numune Training and Research Hospital, Turkey \\ ${ }^{2}$ Department of Histology and Embryology, Institute of Medical Sciences, Imperial School of Medicine, Istanbul, Turkey \\ ${ }^{3}$ Department of Histology and Embryology, Faculty of Medicine, Firat University, Elazig, Turkey \\ ${ }^{4}$ Blood Center of Balcali Hospital, Faculty of Medicine, Cukurova University, Adana, Turkey \\ ${ }^{5}$ Department of Pathology, Faculty of Medicine, Inonu University, Malatya, Turkey \\ A - research concept and design; $B$ - collection and/or assembly of data; $C$ - data analysis and interpretation; \\ $D$ - writing the article; $E$ - critical revision of the article; $F$ - final approval of the article
}

Address for correspondence

Esra Sayglil Yilmaz

E-mail: deryaserbes@gmail.com

\section{Funding sources}

None declared

\section{Conflict of interest}

None declared

\section{Received on February 28, 2017}

Reviewed on April 18, 2017

Accepted on April 27, 2017

\begin{abstract}
Background. There is no study of whether the dysplastic changes in the ovarian surface epithelium of X-ray-exposed rats during hysterosalpingography (HSG) decrease or not with the use of Lipiodol and melatonin given both intraperitoneally (i.p.) and into the suspensorium ovarii.

Objectives. We investigated the restorative effects of melatonin and Lipiodol administration during the HSG procedure on the dysplastic changes in the ovarian surface epithelium of X-ray-exposed rats.

Material and methods. A total of 50 Wistar rats with regular estrous cycles were randomly divided into 5 groups. Group 1 was the control group. In other groups, X-ray was applied (group 2), $0.1 \mathrm{~mL}$ Lipiodol was applied to each uterine horn (group 3), $20 \mathrm{mg} / \mathrm{kg}$ intraperitoneal melatonin application was followed by $0.1 \mathrm{~mL}$ Lipiodol administration to each uterine horn after $15 \mathrm{~min}$ (group 4), and $20 \mathrm{mg} / \mathrm{kg}$ melatonin was administered to the ligamentum suspensorium ovarii, followed by $0.1 \mathrm{~mL}$ Lipiodol application to each uterine horn after $15 \mathrm{~min}$ (group 5). The rats in groups $2-5$ were exposed to whole body radiation 3 times. After $3 \mathrm{~h}$, the abdomens of all rats were reopened and left oophorectomy was performed.
\end{abstract}

Results. The presence of nucleoli and mitosis values were found similar among the groups. All other parameters were significantly higher in group 2 compared to other groups, except for the presence of nucleoli and mitosis values $(p<0.05)$. The presence of hyperchromasia and the total score were found to be the highest in group 2, followed by group 3, when compared to other groups $(p<0.05)$. It was detected that the detrimental effects of $X$-ray exposure diminished with Lipiodol use, and were further reduced by the use of melatonin in combination.

Conclusions. We suggest that the use of melatonin and Lipiodol during HSG may prevent the carcinogenic changes exerted by radiation on the ovarian surface epithelium.

Key words: melatonin, hysterosalpingography, rats, radiation, Lipiodol

DOI

10.17219/acem/70810

Copyright

Copyright by Author(s)

This is an article distributed under the terms of the

Creative Commons Attribution Non-Commercial License

(http://creativecommons.org/licenses/by-nc-nd/4.0/) 


\section{Introduction}

During the last decade, the number of women seeking infertility evaluation has increased significantly. Despite the development of other diagnostic procedures, such as magnetic resonance imaging, hysteroscopy and laparoscopy, hysterosalpingography (HSG) remains as the most valuable and commonly used gynecoradiological technique for the diagnosis of fallopian tube obstruction and uterine cavity abnormalities. ${ }^{1}$

In HSG studies that are performed under fluoroscopic control, various radioscopic exposures are effectuated to visualize the fallopian tubes and the uterine cavity, following the gradual introduction of the contrast medium. ${ }^{2}$ As HSG involves radiation exposure of the gonadal region in women of reproductive capacity and the possibility for repeated examinations, concerns over radiation doses and the associated radiation risks have become an issue. ${ }^{3}$ People are constantly exposed to low levels of radiation because of the common use of certain electronic devices, air travel and medical diagnostic exams. Scientific and technological advancements have further increased the radiation burden in humans. ${ }^{4}$

Ionizing radiation consists of energetic particles and electromagnetic radiation, which can easily penetrate the living tissues or cells. The absorbed energy of ionizing radiation can break chemical bonds and cause the ionization of water and different biologically important macromolecules, such as nucleic acids, membrane lipids and proteins. ${ }^{5}$ Unstable and reactive free radicals, such as hydroxyl radical, superoxide anion and hydrogen peroxide, are produced more rapidly in ionized biological materials. ${ }^{6}$ These free radicals cause the peroxidation of membrane lipids, inactivation of enzymes, depolymerization of polysaccharides, and degradation of nucleic acids. Free radicals can cause severe irreversible damage to the cell membrane. ${ }^{7}$ Cells are well equipped to defend themselves against free radicals, with antioxidant enzymes and molecules. ${ }^{8}$ These antioxidant systems consist of low-molecular-weight antioxidants, like glutathione and melatonin, and antioxidant enzymes, such as superoxide dismutase, catalase and glutathione peroxidase. ${ }^{9}$

The function of melatonin as an antioxidant and a free radical scavenger was first defined by Ianas et al. in 1991.10 Melatonin, a derivative of amino acid tryptophan, is a neurohormone secreted from the pineal glands. However, other organs, such as the retina, ovaries, gastrointestinal tract, and lenses, are also capable of synthesizing melatonin. ${ }^{11}$ Melatonin is considered a quite exceptional antioxidant, because it can easily cross the blood-brain barrier. Studies have shown that it neutralizes hydroxyl radicals, inhibits superoxide radicals through stimulating the mRNA levels for superoxide dismutase, increases glutathione reductase, glutathione peroxidase and glucose-6-phosphate dehydrogenase activities, and decreases the intracellular concentration of hydrogen peroxide. ${ }^{12}$ Lipiodol is iodized ethyl esters of poppy-seed oil fatty acids and has been in use as an iodinated contrast agent since $1926 .{ }^{13}$ It is a liquid, fiducial marker for image-guided radiation therapy (IGRT) used to mark the tumor beds. ${ }^{14}$

There is no study of whether the dysplastic changes in the ovarian surface epithelium of X-ray-exposed rats during HSG decrease or not with the use of Lipiodol and melatonin given both intraperitoneally and into the suspensorium ovarii. Therefore, the aim of this study was to histologically investigate the restorative effects of melatonin and Lipiodol administration during the HSG procedure on the dysplastic changes of the ovarian surface epithelium of rats.

\section{Material and methods}

Following the approval of the Ethics Committee of Firat University (Elazig, Turkey), all surgical procedures and care protocols used were planned and conducted in accordance with the "Guide for the Care and Use of Laboratory Animals". The experiments were performed on $50 \mathrm{fe}$ male albino Wistar rats at the animal laboratory of Firat University. The rats were 5 months old, weighed approx. 200-230 g and had regular ovulation cycles. They were kept at $21-23^{\circ} \mathrm{C}$, with $55-60 \%$ relative humidity, under controlled photo-periods (12:12 h light:dark) and were fed with a standard rodent chow and tap water. Feeding of the rats stopped $18 \mathrm{~h}$ prior to the experiment, only water was allowed. The rats that were detected to be in the estrus phase via vaginal cytology were anesthetized with chloral hydrate $(400 \mathrm{mg} / \mathrm{kg}$, intraperitoneally - i.p.). Each rat was placed on the operating table in a supine position, and the abdomen was opened through a midline incision. The rats were randomized into 5 groups of 10 rats each:

- group 1 (G1): the group in which the abdomen was opened and closed without any X-ray irradiation;

- group 2 (G2): the group in which the abdomen was opened and closed, and X-ray was applied;

- group 3 (G3): the group in which the abdomen was opened and $0.1 \mathrm{~mL}$ Lipiodol ${ }^{\circledR}$ amp. (Guerbet Lab, Aulnaysous-bois, France) was applied to each uterine horn;

- group 4(G4): the group in which the abdomen was opened and $20 \mathrm{mg} / \mathrm{kg}$ melatonin (Melatonin ${ }^{\circledR}, \mathrm{N}$-acetyl5-metoksitriptamin; Sigma Chemicals, Deisenhofen, Germany) was administered i.p., followed by $0.1 \mathrm{~mL}$ Lipiodol ${ }^{\circledR}$ application to each uterine horn after $15 \mathrm{~min}$;

- group 5 (G5): the group in which the abdomen was opened and $20 \mathrm{mg} / \mathrm{kg}$ melatonin (Melatonin ${ }^{\circledR}, \mathrm{N}$-acetyl5-metoksitriptamin; Sigma Chemicals) was administered to the ligamentum suspensorium ovarii, followed by $0.1 \mathrm{~mL}$ Lipiodol ${ }^{\circledR}$ application to each uterine horn after $15 \mathrm{~min}$.

After their abdomens were closed, the rats in G2, G3, G4, and G5 were exposed to whole body irradiation 3 times, leaving 2-minute intervals in between (total dose: 15-20 milirad, Villa-Genius HF-80 X-ray Generator; double table, double 
Table 1. Examined parameters of all groups with respect to the changes in the ovarian surface epithelium

\begin{tabular}{|c|c|c|c|c|c|}
\hline Parameter & G1 & $\mathrm{G} 2$ & G3 & G4 & G5 \\
\hline Stratification & $0.0^{\mathrm{a}}$ & $1.4 \pm 0.5^{b *}$ & $0.0^{\mathrm{a}}$ & $0.0^{\mathrm{a}}$ & $0.0^{\mathrm{a}}$ \\
\hline Tufting & $0.0^{\mathrm{a}}$ & $1.0 \pm 0.4^{\mathrm{b} *}$ & $0.0^{\mathrm{a}}$ & $0.0^{\mathrm{a}}$ & $0.0^{\mathrm{a}}$ \\
\hline Chromatin irregularity & $0.0^{\mathrm{a}}$ & $1.1 \pm 0.3^{b *}$ & $0.0^{a}$ & $0.0^{\mathrm{a}}$ & $0.0^{\mathrm{a}}$ \\
\hline Nuclear contour irregularity & $0.0^{\mathrm{a}}$ & $1.4 \pm 0.5^{b *}$ & $0.4 \pm 0.5^{a}$ & $0.0^{\mathrm{a}}$ & $0.0^{\mathrm{a}}$ \\
\hline Increase in nucleus size & $0.0^{\mathrm{a}}$ & $1.9 \pm 0.3^{b *}$ & $0.4 \pm 0.5^{a}$ & $0.2 \pm 0.4^{a}$ & $0.1 \pm 0.3^{a}$ \\
\hline Increase in nucleus/cytoplasm ratio & $0.0^{\mathrm{a}}$ & $2.6 \pm 0.5^{b *}$ & $0.4 \pm 0.5^{a}$ & $0.2 \pm 0.4^{a}$ & $0.1 \pm 0.3^{a}$ \\
\hline Pleomorphism & $0.0^{\mathrm{a}}$ & $1.0 \pm 0.0^{b *}$ & $0.0^{\mathrm{a}}$ & $0.0^{\mathrm{a}}$ & $0.0^{\mathrm{a}}$ \\
\hline Hyperchromasia & $0.2 \pm 0.4^{\mathrm{a}}$ & $2.3 \pm 0.8^{b *}$ & $1.0 \pm 0.0^{c *}$ & $0.2 \pm 0.4^{a}$ & $0.2 \pm 0.4^{\mathrm{a}}$ \\
\hline Presence of nucleoli & 0.0 & 0.0 & 0.0 & 0.0 & 0.0 \\
\hline Presence of mitosis & 0.0 & 0.0 & 0.0 & 0.0 & 0.0 \\
\hline Total & $0.2 \pm 0.4^{\mathrm{a}}$ & $12.7 \pm 1.7^{\mathrm{b} *}$ & $2.3 \pm 1.7^{\star *}$ & $0.6 \pm 1.2^{\mathrm{a}}$ & $0.4 \pm 0.9^{a}$ \\
\hline
\end{tabular}

Values shown are means \pm standard deviation (SD). The letters a-c indicate statistical differences among the groups ( $p<0.005, \mathrm{Mann}-\mathrm{Whitney} U$ test); * groups with parameters significantly different from control (G1).

tube) (Del Medical, Milan, Italy). During the experiment, the blood pressure, heart rate and body temperature of the rats were monitored. After $3 \mathrm{~h}$, the abdomens of all rats were reopened and left oophorectomy was performed. Samples from the left ovaries were embedded into paraffin blocks after fixing in 10\% formaldehyde for histologic examination, and then sliced into 4-micrometer thick sections.

After the preparations were stained with hematoxylineosin, changes in the ovarian surface epithelium were examined according to the endometrium ablation scale. ${ }^{15}$ According to the scale, 1 . stratification; 2. tufting; 3 . chromatin irregularity; 4 . nuclear contour irregularity; 5 . increase in nucleus size; 6 . increase in nucleus/cytoplasm ratio; 7. pleomorphism; 8. presence of nucleoli; 9. mitosis; and 10. hyperchromasia changes in the ovarian surface epithelium were examined. For each parameter, a scale (none $=0$ points, present $=1$ point, considerably present $=2$ points) was applied, and the total score was obtained based on the values of all the parameters in a preparation.

The Kruskal-Wallis variance test from the SPSS Package Software (IBM, Armonk, USA) was used in the statistical analysis of data. The Mann-Whitney U test with Bonferroni correction was applied for parameters with $\mathrm{p}<0.05$. A probability value of $\mathrm{p}<0.005$ was considered statistically significant.

\section{Results}

The presence of nucleoli and mitosis values were found similar in all groups ( $p>0.05$, Kruskal-Wallis variance test).

All parameters except nucleoli and mitosis values increased significantly in the X-ray exposed group compared to other groups ( $\mathrm{p}<0.005$, Mann-Whitney U test).

The detrimental effects of X-ray application diminished with Lipiodol use and were further reduced by the use of melatonin in combination with Lipiodol.
The presence of hyperchromasia and the total score were found to be the highest in group 2, followed by group 3, compared to other groups ( $\mathrm{p}<0.005$, Mann-Whitney U test). All examined parameters are listed in Table 1.

\section{Discussion}

The ovaries are a part of the female reproductive system that is very sensitive to radiation. Ovarian damage is a major complication observed in patients who receive longterm radiotherapy. High doses of radiotherapy damage the ovarian function of all ages, causing a decline in fertility. ${ }^{16}$ Therefore, researchers' interest in rat estrus cycle studies has increased in order to prevent ovarian damage caused by radiation, to discuss the effects of radiotherapy and to evaluate normal ovarian function.

The total number of follicles is regarded as one of the most important parameters reflecting ovarian function. ${ }^{17}$ Lee et al. investigated the damage in primordial and primary follicles by collecting the ovaries of female prepubertal mice exposed to 8.3 Gy gamma radiation after 3, 6 and $12 \mathrm{~h}$ after irradiation. ${ }^{18}$ They reported that the most damage occurred after $3 \mathrm{~h}$ of irradiation, and the damage decreased as exposure time progressed. For this reason, in order to determine the dysplastic changes in the rat ovarian surface epithelium, the ovarian tissues were collected after $3 \mathrm{~h}$ of exposure and histologically evaluated for each group. Our study demonstrated that the radiation received during HSG treatment significantly increased stratification, tufting, chromatin irregularity, nuclear contour irregularity, nucleus size, nucleus/cytoplasm rate, pleomorphism, and hyperchromasia in the rat ovarian surface epithelium. Similarly, Pala et al. reported that markedly increased epithelial degeneration and obstruction was observed in the endometrial glands of rats that were exposed to X-ray irradiation with Lipiodol, as compared 
to other groups. ${ }^{19}$ Said et al. reported degeneration of the mucosal lining epithelial cell layers of the uteri in rats that were exposed to gamma radiation. ${ }^{20}$ Radiation triggers carcinogenic changes in the ovarian surface epithelium. Our results were similar to the histological changes observed in radiation-exposed normal cells. ${ }^{21,22}$

Our study confirmed that the detrimental effects of X-ray application in the rat ovarian surface epithelium were significantly diminished with Lipiodol application. This may be due to the fact that linoleic acid, an antioxidant constituent of Lipiodol, has a cytotoxic effect on macrophages, reducing the production of reactive oxygen species (ROS) in the ovaries and having antiproliferative activity. Sapmaz and Akpolat reported that Lipiodol use significantly diminished the dysplastic changes in luminal epithelial cells of rats that were exposed to X-ray irradiation. ${ }^{23}$ In previous studies, Lipiodol uptake by the cancer cells and by the endothelial cells was demonstrated on light and electron microscopy as early as $3 \mathrm{~h}$ after I-lipiodol application. Lipiodol is rapidly taken up and retained in the cells in the form of cytoplasmic bound vesicles. ${ }^{24}$ It also has a role as a vehicle to carry other agents inside the cells. ${ }^{25}$ Sapmaz et al. examined the effects of Lipiodol and Lipiodol combined with tetracycline against X-ray exposure during HSG treatment, and reported that Lipiodol use diminished the carcinogenic effects of radiation on ovarian surface epithelium, and were further reduced by the use of tetracycline in combination with Lipiodol. ${ }^{15}$

The protective effects of melatonin against oxidative stress have been established in in vitro and in vivo studies. ${ }^{26-28}$ During antioxidant defense, melatonin not only neutralizes hydroxyl radicals, but also scavenges peroxyl radicals and singlet oxygen throughout peroxidation. ${ }^{29}$ This implies that melatonin, which is lipophilic and hydrophilic, has effects not only at the cellular level, but also in the subcellular compartments. ${ }^{30}$ Melatonin stimulates the activity of the detoxifying enzyme glutathione peroxidase and strengthens the antioxidant defense of the cells against oxidative stress. ${ }^{31}$ That is how melatonin stimulates antioxidant defense or exhibits strengthening actions against ionizing radiation which causes genetic damage by increasing the production of free radicals. ${ }^{32}$ In our study, changes in ovarian surface epithelium in rats treated with Lipiodol and melatonin were found to be similar to the control group. Sapmaz and Akpolat reported that the use of melatonin in combination with Lipiodol has a decreasing effect on congestion, endometrial ablation, fibrosis, and dysplastic changes to the control levels in X-ray-treated rats. ${ }^{23}$ It is thought that this decreasing effect is due to the stimulation of the antioxidant defense system of the cells against the damage caused by ionizing radiation by elevated intracellular concentrations of melatonin with Lipiodol's action. Radiation causes arteritis in large vessels such as coronary, pulmonary, thoracic aorta, brachial, renal, and ilio-femoral vessels, and causes hypoxia and ischemia in the perfused organs. ${ }^{33,34}$ In our study, the rats in the X-ray group may have developed a more severe radiation-associated ilio-femoral or uterine arteritis than the rats in the groups G3, G4 and G5. This may have led to a severe hypoxic effect and an increase in ROS production in G2, leading to the onset of carcinogenic changes in the ovarian surface epithelium. Even though other groups developed radiation-associated ilio-femoral or uterine arteritis of similar severity, it is thought that the combined use of Lipiodol and melatonin, which have antioxidant properties, was effective in reducing the detrimental effects of radiation. The study conducted by Badr et al. on rats confirmed that melatonin treatment $1 \mathrm{~h}$ before the X-ray irradiation prevented chromosomal damage, but no significant effect was observed when melatonin was given $1 / 2 \mathrm{~h}$ after the exposure. ${ }^{30}$ Undeger et al. demonstrated that intraperitoneal pretreatment of rats with $100 \mathrm{mg} / \mathrm{kg}$ melatonin provided a significant decrease in the DNA strand breakage and lipid peroxidation in the brain tissue. ${ }^{35}$ Canyllmaz et al. reported that $100 \mathrm{mg} / \mathrm{kg}$ intraperitoneal melatonin administration $1 / 2 \mathrm{~h}$ prior to a single dose of 6-Gy-gamma irradiation decreased the tubular atrophy and lipid peroxidation in the rat kidney tissues. ${ }^{36}$ Sato et al. conducted a study in order to reduce the risk for postoperative acute liver failure, in which prostaglandin was administered either from the hepatic artery or superior mesenteric artery to patients who were undergoing major hepatic resections, and found that prostaglandin applied through the hepatic artery was infused more rapidly. ${ }^{37}$ In our study, melatonin was administered in 2 different ways prior to irradiation, intraperitoneally (G4) and into the suspensorium ovarii (G5). Although both groups were at the control level, it was determined that the values of G5 were better than those of G4. This suggests that antioxidants may increase their protective effects if administered closer to the target organs. Pala et al. reported that there was no significant difference in epithelial degeneration and congestion in rats administered with Lipiodol combined with vitamin $C$ and Lipiodol combined with vitamin $\mathrm{E}$ i.p. prior to irradiation, indicating that both groups were at the control level. ${ }^{19}$ Sapmaz et al. reported that melatonin was more effective than oxytetracycline in their comparative study of the antioxidant effects of melatonin and oxytetracycline in autologous intraperitoneal ovary transplantation. ${ }^{38}$ Histoenzymological and morphological studies suggested that melatonin was shown to act synergistically with chemotherapeutic agents or radiotherapy in order to increase the antitumor effects by promoting disease stabilization. ${ }^{39}$ Therefore, it is believed that melatonin and Lipiodol administration to patients prior or during the HSG procedure can reduce the harmful effects of radiation. Based on the results of our work, it is thought that melatonin and Lipiodol administration may prevent the carcinogenic changes exerted by radiation on the ovarian surface epithelium. 


\section{References}

1. Úbeda B, Paraira M, Alert E, Abuin RA. Hysterosalpingography: Spectrum of normal variants and nonpathologic findings. ASSS. 2001;177: 131-135.

2. Perisikanis K, Damilakis J, Grammatikakis J, Therocharopolus N, Gourtsayiannis N. Radiogenic risk from hysterosalpingography. Eur Radiol. 2003;13:1522-1528.

3. Yousef M, Tambul JY, Sulieman A. Radiation dose measurements during hysterosalpingography. Sudan Medical Monitor. 2014;9(1):15-19.

4. Jagetia GC, Reddy TK. Modulation of radiation-induced alteration in the antioxidant status of mice by naringin. Life Sci. 2005;77(7): 780-794.

5. Lett JT. Damage to cellular DNA from particulate radiations, the efficacy of its processing and the radiosensitivity of mammalian cells. Emphasis on DNA double strand breaks and chromatin breaks. Radiat Environ Biophys. 1992;31(4):257-277.

6. Robbins MEC, Zhao W. Chronic oxidative stress and radiation late normal tissue injury: A review. Int J Radiat Biol. 2004;80(4):251-259.

7. Yalinkilic $\mathrm{O}$, Enginar $\mathrm{H}$. Effect of $\mathrm{X}$-radiation and lipid peroxidation and antioxidant system in rats treated with saponin-containing compound. Photochem Photobiol. 2008;84(1):236-242.

8. Jagetia GC, Vankatesha VA, Reddy TK. Naringin, a citrus flavonone, protects against radiation-induced chromosome damage in mouse bone marrow. Mutagenesis. 2003;18:337-343.

9. Jeon WY, Lee MY, Shin HS, Shin HK. Protective effects of the traditional herbal formula oryeongson water extract on ethanol-induced acute gastric mucosal injury in rats. Evid Based Complement Alternat Med. 2012;1-9. doi: 10.1155/2012/438191

10. Ianas O, Oliverscu R, Badescu I. Melatonin involvement in oxidative processes. Rom J Endocrinol. 1991;29:117-123.

11. Reiter RJ, Tan DX, Qi W, Manchester LC, Karbownik M, Calvo JR. Pharmacology and physiology of melatonin in the reduction of oxidative stress in vivo. Biol Signals Recept. 2000;9(3-4):160-171.

12. Ozcelik F, Erdem M, Bolu A, Gulsun M. Melatonin: General features and its role in psychiatric disorders. Current Approach in Psychiatry. 2013;5(2):179-203.

13. Freilich JM, Spiess PE, Biogoli ME, et al. Lipiodol as a fiducial marker for image-guided radiation therapy for bladder cancer. Int Braz J Urol. 2014;40(2):190-197.

14. Baumgarten AS, Emtage JB, Wilder RB, Biagioli AS, Gupta S, Spiesu PE. Intravesical lipiodol injection technique for image-guided radiation therapy for bladder cancer. Urology. 2014;83:946-950.

15. Sapmaz E, Akpolat N, Çelik A, Sapmaz T, Pala S, Hanay F. Examination of the effect of HSG procedure on ovarian surface epithelium: Experimental study. J Turk Soc Obstet Gynecol. 2006;3:112-117.

16. Bricaire L, Larache E, Bourcigoux N, Daradille B, Christin-Maitre S. Premature ovarian failure. Presse Med. 2013;42(11):1500-1507.

17. Zhang XF, Zhang LJ, Li L, et al. Diethylhexyl phthalate exposure impairs follicular development and affects oocyte maturation in the mouse. Environ Mol Mutagen. 2013;54:354-361.

18. Lee CJ, Park HH, Do BR, Yoon Y, Kim JK. Natural and radiation-induced degeneration of primordial and primary follicles in mouse ovary. Anim Reprod Sci. 2000;59(1-2):109-117.

19. Pala $S$, Atilgan R, Kuloglu T, et al. Protective effects of vitamin $C$ and vitamin E against hysterosalpingography-induced epithelial degeneration and proliferation in rat endometrium. Drug Des Devel Ther. 2016;4079-4089.

20. Said RS, Nada AS, El-Demerdash E. Sodium selenite improves folliculogenesis in radiation-induced ovarian failure: A mechanistic approach. PLoS One. 2012;7(12):e50928.
21. Preston RJ. Radiation biology: Concepts for radiation protection. Health Phys. 2005;88(6):545-556.

22. Abe $S$, Otsuki M. Styrene maleic acid neocarzinostatin treatment for hepatocellular carcinoma. Curr Med Chem Anticancer Agents. 2002;2(6): 715-726.

23. Sapmaz E, Akpolat N. Examination of the effects of pre-HSG melatonin on endometrial ablation and uterine dysplasic cell development associated with radiation. Firat Tip Dergisi. 2012;17(1):1-5.

24. Al Mufti R, Pedley RB, Marshall D, et al. In vitro assessment of Lipiodol-targeted radiotheraphy for liver and colorectal cancer cell lines. Br J Cancer. 1999;79:1665-1671.

25. Kishimoto S, Miyazawa K, Fukushima S, Takeuchi Y. In vitro antitumor activity intracellular accumulation and DNA adduct formation of cis-[((1R,2R)-1,2-cyclohexanediamine- $\left.N, N^{\prime}\right)$ bis(myristato)] platinum (II) suspended in lipiodol. Jpn J Cancer Res. 2000;91(1):99-104.

26. Sewerynek E, Reiter RJ, Melchiorri D, Ortiz GG, Lewinski A. Oxidative damage in the liver induced by ischemia-reperfusion: Protection by melatonin. Hepatogastroenterology. 1996;43:898-905.

27. Princ FG, Juknat AA, Maxit AG, Cardalda C, Battle A. Melatonin's antioxidant protection against delta-aminolevulinic acid-induced oxidative damage in rat cerebellum. J Pineal Res. 1997;23:40-46.

28. Melchiorri D, Reiter RJ, Sewerynek E, Hara M, Chen L, Nistico G. Paraquat toxicity and oxidative damage. Reduction by melatonin. Biochem Pharmacol. 1996;51:1095-1099.

29. Reiter RJ. Functional pleiotropy of neurohormone melatonin: Antioxidant protection and neuroendocrine regulation. Front Neuroendocrinol. 1995;16(4):383-415.

30. Badr FM, El Habit OH, Harraz MM. Radioprotective effect of melatonin assessed by measuring chromosomal damage in mitotic and meiotic cells. Mutat Res. 1999;444(2):367-372.

31. Pablos MI, Chuang JI, Reiter RJ, et al. Time course of melatonininduced increase in glutathione peroxidase activity in chick tissues. Biol Signals. 1996;4:324-330.

32. Melchiorri D, Ortiz GG, Reiter RJ, et al. Melatonin reduces paraquatinduced genotoxicity in mice. Toxicol Lett. 1998;95(2):103-108.

33. Rubin DI, Schomberg PJ, Shepherd RF, Panneton JM. Arteritis and brachial plexus neuropathy as delayed complications of radiation therapy. Mayo Clin Proc. 2001;76(8):849-852.

34. Bigot JM, Mathieu D, Reizine D. Radiation arteriopathies. Ann Med Interne (Paris). 1983;134(5):411-415.

35. Undeger U, Giray B, Zorlu AF, Oge K, Bacaran N. Protective effects of melatonin on the ionizing radiation induced DNA damage in the rat brain. Exp Toxicol Pathol. 2004;5:379-384.

36. Canyılmaz E, Uslu GH, Bahat Z, et al. Comparison of the effects of melatonin and genistein on radiation induce nephrotoxicity results of an experimental study. Biomed Rep. 2016;4(1):45-50.

37. Sato T, Yasui O, Kurokawa T, Asanuma Y, Koyama K. Appraisal of intraarterial infusion of prostaglandin E1 in patients undergoing major hepatic resection report of four cases. Tohoku J Exp Med. 2001;195(2): 125-133.

38. Sapmaz E, Ayar A, Celik H, Sapmaz T, Kilic N, Yasar MA. Effects of melatonin and oxytetracycline in autologous intraperitoneal ovary transplantation in rats. Neuro Endocrinol Lett. 2003;24(5):350-354.

39. Sener G, Atasoy BM, Ersoy Y, Arbak S, Sengoz M, Yegen BC. Melatonin protects against ionizing radiation induced oxidative damage in corpus cavernosum and urinary bladder in rats. J Pineal Res. 2004;37:241-246. 